\title{
Importance of Lone Pair Interactions/Redistribution in Hard and Soft Ligands within the Active Site of Alcohol Dehydrogenase Zn-metalloenzyme: Insights from Electron Localization Function
}

\author{
B. DE COURCY ${ }^{1}$, N. GRESH ${ }^{1 *}$, J.-P. PIQUEMAL ${ }^{2,3 *}$ \\ ${ }^{1}$ (Laboratoire de Pharmacochimie Moléculaire et Cellulaire, U648 INSERM, UFR Biomédicale, \\ Université Paris Descartes, 45, rue des Saints-Pères, 75006 Paris, France) \\ ${ }^{2}$ (UPMC Univ Paris 06, UMR 7616, Laboratoire de Chimie Théorique, case courrier 137, \\ 4 place Jussieu, F-75005 Paris, France) \\ ${ }^{3}$ (CNRS, UMR 7616, Laboratoire de Chimie Théorique, case courrier 137, 4 place Jussieu, F-75005 Paris, France)
}

Received 27 October 2008 / Revised 18 November 2008 / Accepted 3 December 2008

\begin{abstract}
As a continuation of our previous work (de Courcy et al., 2008. J. Chem. Theo. Comput. 4 1659), lone pair-cation interactions were quantum-mechanically studied within the active site of the alcohol dehydrogenase $\mathrm{Zn}$ (II)-metalloenzyme by means of the topological analysis of the Electron Localization Function (ELF) and the Reduced Variational Space (RVS) energy decomposition analysis. Ligands lone pairs in direct interaction with the metal were shown to control the physical nature of the interaction as it appears to be dominated by polarization when the number of interacting lone pairs increases. Furthermore, we observed a peculiar behaviour of the cysteinate $\mathrm{S}^{-}$lone pairs which can redistribute and merge, thereby reducing their number to accommodate the zinc cation which also exhibits a consequent plasticity of its density outer shells which can delocalize towards ligands. Such observations should allow a deeper understanding of the usual softness/hardness concept of ions and ligands.
\end{abstract}

Key words: zinc, metalloenzyme, lone pair, electron localization function (ELF), alcohol dehydrogenase, energy decomposition analysis, hardness, softness.

\section{Introduction}

Alcohol dehydrogenase (ADH) is a $\mathrm{Zn}(\mathrm{II})$ metalloenzyme which catalyses the oxidation of alcohol into aldehyde or ketone through concerted reduction of oxidized nicotinamide dinucleotide (NAD), denoted as $\mathrm{NAD}+$, into a reduced form, denoted as NADH. Such a reversible reaction occurs in human liver as $\mathrm{ADH}$ is part of the regulation mechanism of ethanol which can be toxic when present at high concentration (Crow et al., 1989; de Courcy et al., 2008). The binding site of ADH has two anionic cysteinate residues, and one histidine. $\mathrm{Zn}$ (II) coordination is completed by the oxygen of the ethanol substrate. A Phe residue has a stacking interaction with ethanol and could thus further contribute to stabilization by an indirect cation- $\pi$ interaction with Zn(II) (Li et al., 1994; de Courcy et al., 2008). Such a motif has been reviewed by Zaric et al. (Zaric et al.,

\footnotetext{
*Corresponding authors.

E-mail: jpp@lct.jussieu.fr

E-mail: nohad.gresh@univ-paris5.fr
}

2000). We have recently quantified the contribution of Phe to the overall stability of the binding site and the weights of first-order, second-order, and dispersion/correlation. Thus we investigated the ADH binding site (de Courcy et al., 2008) by means of the Sum of Interaction Between ab initio Fragments (SIBFA) anisotropic polarizable molecular mechanics (APMM) approach (Gresh et al., 2007) coupled to ab initio energy decomposition analysis. Thus was done both in the absence and in the presence of the benzene ring modelling the Phe residue. Usually, non-additivity phenomena in interaction energies are associated to the polarization, charge transfer and dispersion/correlation contributions. In the case of $\mathrm{ADH}$, we had shown the polarization energy associated to the benzene ring to be completely cancelled due to anticooperative many-body effects. Therefore, benzene would not contribute to complex stabilization unless electron correlation was embodied at the quantum or APMM levels. Indeed, it was shown in the context of ab initio MP2 and SIBFA that if dispersion/electron correlation is present the stabilization energy it contributes is in 
the $3-9 \mathrm{kcal} / \mathrm{mol}$ range. In the present contribution, we aim to go further into the understanding of the many-body effects in such an enzyme with quantum chemistry. To do so, we use the topological analysis of the Electron Localization Function (ELF) (Becke and Edgecombe, 1990; Silvi et al., 1994) to analyze at an atomic level, the deformation and perturbation of the electron density of the $\mathrm{ADH}$ binding site in the presence of the ethanol substrate. We focus here on the local deformations of the electron densities of the Zn-coordinating $\mathrm{S}, \mathrm{O}$ and $\mathrm{N}$ atoms as well on the ligands effects on the metal cation. Ligand-metal interactions are further studied by means of intermolecular energy decomposition analysis.

\section{Methods}

\subsection{The electron localization function (ELF)}

The ELF function (Becke and Edgecombe, 1990) can be interpreted as a measure of the Pauli repulsion in the atomic or molecular space and enables access to the probability of finding two same spin electrons: ELF is defined to have values restricted between 0 and 1 and can be interpreted as a signature of the electronic pair distribution but, in contrast to pair functions, it can be more easily calculated and interpreted. Once computed on a 3D grid from a given ab initio wave function, the ELF function can be partitioned into an intuitive chemical scheme (Silvi et al., 1994). Indeed, core regions, denoted $\mathrm{C}(\mathrm{X})$, can be determined for any atom. This is also the case for valence regions associated to lone pairs, denoted $\mathrm{V}(\mathrm{X})$, and for chemical bonds $(\mathrm{V}(\mathrm{X}$, $\mathrm{Y})$ ). These ELF regions, the so-called basins (denoted $\Omega$ ), match closely the domains of Gillespie's VSEPR (Valence Shell Electron Pair Repulsion) model (Gillespie et al., 2005).

In addition to a visualization of the ELF isosurfaces, ELF offers the possibility to integrate the population (numbers of electrons) within a basin or to obtain local distributed electrostatic moments such as dipoles and quadrupoles (Pilmé and Piquemal, 2008). Details about ELF and its applications to bioinorganic chemistry can be found in a recent review paper (Piquemal et al., 2008).

\section{Computational details.}

All ELF grids (of size $180^{*} 180^{*} 180$ for the population analyzes and of size $300^{*} 300^{*} 300$ to improve rendering for the Figures) were generated using the molecular orbitals computed with Gaussian 03 (Frisch et al., 2007) at the B3LYP/6-311++ $\mathrm{G}^{* *}$ level (Becke, 1988; Lee, 1988; Krishnan et al., 1980; Mc Lean et al., 1980; Rassolov, 1998). These ELF computations were performed using a modified TOP-MOD package (Noury et $a l ., 1999)$. As MP2 computations embodying disper- sion cannot be used directly in the TOPMOD package due to present implementation limitation, DFT computations were presently employed to describe such a system. As computations were performed at fixed geometries (the Cartesian coordinates were those previously derived by SIBFA energy minimizations, see de Courcy et al., 2008), DFT should clearly perform an accurate treatment of the studied polarization effects (Piquemal et al., 2008). Such an assumption was verified by computing Mulliken and Atoms in Molecules (AIM) (Bader, 1990) charges which were found to be in good agreement between MP2 and B3LYP. The energy decomposition analysis used the Reduced Variational Space (RVS) procedure (Stevens and Fink, 1987) as implemented in the GAMESS software (Schmidt et al., 1993) and done at the HF/CEP 4-31G(2d) level (Stevens et al., 1984). RVS decomposes the $\Delta \mathrm{E}$ total interaction energy into electrostatic, exchange-repulsion, polarization and charge transfer contributions. We have used the standard notation E1 (first-order) energy for the sum of electrostatic and exchange-repulsion and E2 (secondorder) energy for the sum of polarization and charge transfer (the so-called induction). The investigated complexes encompassed the ethanol substrate and the end side-chains of histidine, cysteine, and phenylalanine, namely imidazole, cysteinate, and benzene. They do not include the side-chain $\mathrm{C} \beta$ methylenes, which are devoid of lone pairs, nor the main-chains, which being farther from $\mathrm{Zn}$ (II) should undergo much lesser perturbations. The two Cys residues were considered to be deprotonated, consistent with previous results on $\mathrm{Zn}$ fingers having two Zn-coordinating Cys residues (Maynard et al., 2001; Simonson et al., 2002). The preliminary SIBFA optimization (de Courcy et al., 2008) was motivated by an unsatisfactory short distance between $\mathrm{Zn}(\mathrm{II})$ and the sulphur atom of Cys174 within the available crystallographic structure (Zaric et al., 2000), i.e. $2 \AA$ against an expected 2.2- $2.3 \AA$ distance. Such an optimized binding site is displayed on Figure 1.

\section{Results}

Figure 2 displays a representation of the ELF function for our $\mathrm{ADH}$ model. As we can see, the $\mathrm{Zn}$ (II) electron density is split into several basins which appear delocalized (except one) from the atom position. Indeed, being polarized by the ligands, they point towards the coordinated ligand atom cores: namely the two cysteinate $\mathrm{S}^{-}$atoms, the $\mathrm{N}$ imidazole nitrogen and the ethanol oxygen. Linking this metal basin splitting to polarization is possible by computing the RVS cation polarization energy which appears to be non null (de Courcy et al., 2008). Moreover, it is also possible to directly verify the value of the local dipole component of the $\mathrm{Zn}(\mathrm{II})$ cation within the complex using the Distributed Electrostatic Moments based on the ELF 


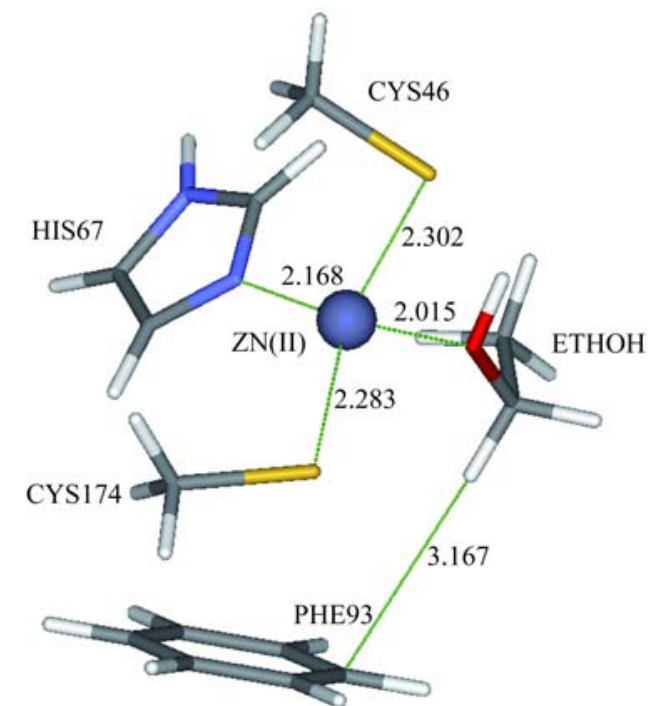

Fig. 1 Representation of the optimized active site of ADH



Fig. 2 ELF representation of the ADH active site (left). Zoom on the $\mathrm{Zn}(\mathrm{II})$ split delocalized valence in interaction with ligands (right). $(\eta=0.8)$

Partition approach (DEMEP) or AIM analysis (Pilmé and Piquemal, 2008) which is clearly showing a non null integrated dipole moment associated to the $\mathrm{Zn}$ (II) atom (this dipole is zero for an isolated $\mathrm{Zn}(\mathrm{II})$ ). Table 1 displays the volumes and populations for each ELF localization basin of $\mathrm{Zn}(\mathrm{II})$. As we can see, the sum of the basin population reaches 28 electrons, an indication of a purely electrostatic/polarization interaction as Zn(II) is not sharing electrons with its environment. The first basin (number 1) is the present active core of $\mathrm{Zn}(\mathrm{II})$ as the other basins constitute its outer-shell electrons
Table 1 Electronic distribution of the $\mathrm{Zn}$ (II) electrons in the ADH complex

\begin{tabular}{ccc}
\hline Basins & Volumes $\left(\AA^{3}\right)$ & Populations \\
\hline $\mathrm{C}(\mathrm{Zn}) 1$ & 0.41 & 10.76 \\
$\mathrm{C}(\mathrm{Zn}) 2$ & 7.66 & 3.55 \\
$\mathrm{C}(\mathrm{Zn}) 3$ & 4.56 & 3.91 \\
$\mathrm{C}(\mathrm{Zn}) 4$ & 6.84 & 3.57 \\
$\mathrm{C}(\mathrm{Zn}) 5$ & 10.93 & 6.21 \\
\hline
\end{tabular}

(basins numbered 2 to 5 ). Basins 2 and 4 exhibit an identical population and point towards the cysteinates. Basin 3 points towards imidazole and basin 5 points towards ethanol. An important issue in this site relates to the lone pairs borne by the $\mathrm{N}, \mathrm{S}$ and $\mathrm{O}$ ligands. Figure 3 displays the positions of the lone pairs present in uncomplexed imidazole, ethanol and cysteinate. No drastic changes can be seen for the imidazole and ethanol lone pairs upon complexation as only small distortions occur. However, while Figure 3 shows three well-separated lone pairs on the uncomplexed cysteinate sulphur, only two lone pairs on each $\mathrm{S}$ atom are found upon complexation. Figure 4 shows the superposition of the centers of each ELF basin (the so-called ELF attractors) for the lone pairs in the complex on the one hand and in isolation on the other hand. These are displayed in violet and in orange respectively. A first examination of the positions of the non-coordinated sulphur lone pairs reveals that these latter are directly facing $\mathrm{Zn}(\mathrm{II})$ at a very short distance of $1.37 \AA$. For this reason, upon coordination, one of the negatively charged $\mathrm{S}^{-}$lone pairs is rejected by the $\mathrm{Zn}$ (II) to the opposite side of cysteinate due to a local excess of Pauli repulsion caused by its large volume. The density of this lone pair thus appears to be redistributed within the two other lone pair basins. Whereas lone pair towards bond density redistribution were shown in the case of the interconversion of the $\mathrm{Cu} 2 \mathrm{O} 2$ metallic core of metalloenzymes such as tyrosinase (Piquemal and Pilmé, 2006), such a peculiar lone pair behaviour is unraveled here for the first time. Such an electron density plasticity is also linked to the observed core-valence redistributions previously observed for $\mathrm{AX}_{6} \mathrm{E}$ complexes $(\mathrm{X}=\mathrm{Cl}, \mathrm{Br}, \mathrm{I} ; \mathrm{A}=\mathrm{Sn}, \mathrm{Be}, \mathrm{Bi}, \mathrm{Sb}$ or Te; E denotes the lone pair belonging to A in the VSEPR theory (Gillespie et al., 2005)) and for the lead cation $(\mathrm{Pb}(\mathrm{II})) 6 \mathrm{~s}^{2}$ lone pair (Pilmé et al., 2006; Gourlaouen et al., 2008; and references therein). In that case, when the number of ligands increases, such a lone pair merges into the metal core in disagreement with the Valence Shell Electron Pair Repulsion (VSEPR) model. By contrast, in the $\mathrm{ADH}$ model, the ligands $\mathrm{N}$ and $\mathrm{O}$ lone pairs are at a larger distance from $\mathrm{Zn}(\mathrm{II})$ and are only contracted around the nuclei of their atom bearers as a result of metal coordination. Table 2 reports the lone pair volumes and populations in both uncomplexed and 
complexed states. The numerical values extracted from the ELF topological analysis confirm the visual examination, showing two lone pairs on $\mathrm{S}^{-}$in the complex as opposed to three ones in uncomplexed cysteinate. An identical number of lone pairs is found on the other hand for the $\mathrm{N}$ and $\mathrm{O}$ atom ligands but with a noticeable volume contraction upon complexation.

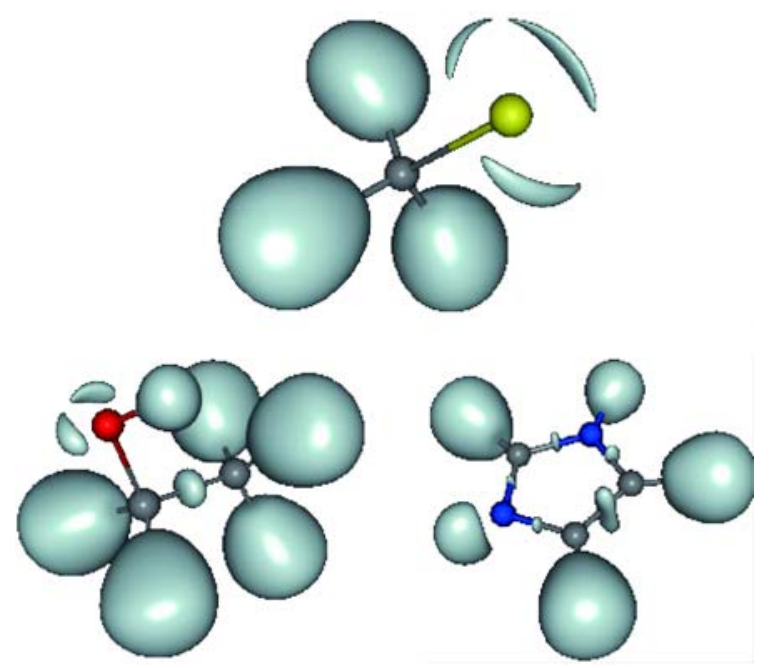

Fig. 3 ELF representation $(\eta=0.85)$ of the lone pairs for isolated fragments: namely cysteinate, ethanol and imidazole (from left to right). They are located on sulphur, oxygen and nitrogen respectively

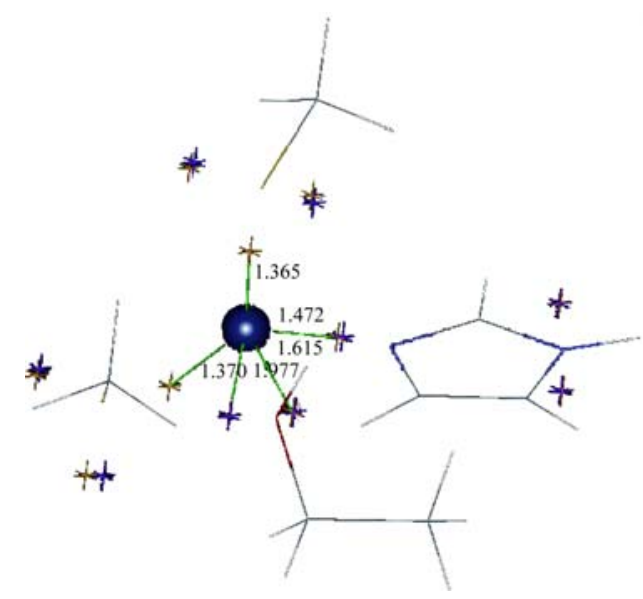

Fig. 4 Superposition of the ELF attractors for the lone pairs of the fragments constituting $\mathrm{ADH}$ in their two states: i.e., considered within the complex (violet) or not (orange)

In fact, in the complex, no cysteinate lone pair faces directly $\mathrm{Zn}(\mathrm{II})$ as the interaction involves the sulphur core only. On the opposite, the imidazole and the ethanol fragments interact through their $\mathrm{N}$ and $\mathrm{O}$ lone pairs respectively. The aptitude of anionic sulphur to redistribute its electron density in space reflects its wellknown 'softness', itself related to its high polarizability. The impact of the latter was highlighted in joint
RVS and SIBFA studies that bore on the complexes of methanethiolate with divalent cations (Garmer and Gresh, 1994; Gresh et al., 1995; Gresh, 1995).

Table 3 displays the results of several energy decomposition analyses previously performed (de Courcy et al., 2008) using the RVS approaches on the monoligated complexes of $\mathrm{Zn}(\mathrm{II})$ with $\mathrm{Cy}^{-}$, imidazole (Imh), and ethanol (EtOH).

Table 3 Relative weights of first $\left(E_{1}\right)$ and second $\left(E_{2}\right)$ order energies for the four $\mathrm{Zn}(\mathrm{II})$ monoligated complexes involved in the ADH binding site. Imh denotes the imidazole ring

\begin{tabular}{ccc}
\hline & $\mathrm{E}_{1} / \mathrm{E}$ & $\mathrm{E}_{2} / \mathrm{E}$ \\
\hline $\mathrm{Cy}^{-} 46 / \mathrm{Zn}(\mathrm{II})$ & $66,8 \%$ & $33,2 \%$ \\
$\mathrm{Imh} / \mathrm{Zn}(\mathrm{II})$ & $44,1 \%$ & $55,9 \%$ \\
$\mathrm{Cy}^{-} 174 \mathrm{Zn}(\mathrm{II})$ & $67,1 \%$ & $32,9 \%$ \\
$\mathrm{EtOH} / \mathrm{Zn}(\mathrm{II})$ & $39,7 \%$ & $60,3 \%$ \\
\hline
\end{tabular}

It is then possible to extract the relative weights of the first-order term $\mathrm{E}_{1}$, which is dominated by electrostatics, and of the second-order one, $\mathrm{E}_{2}$, which is dominated by polarization and charge transfer. RVS and SIBFA analyses using the CEP 4-31G(2d) basis set have shown the monoligated complexes of $\mathrm{Zn}(\mathrm{II})$ with cysteinate at equilibrium distance to be predominantly electrostatic, E1 having a much larger numerical weight than $\mathrm{E}_{2}$ in spite of the very large values of $\mathrm{E}_{\mathrm{pol}}$ and $\mathrm{E}_{\mathrm{ct}}$ (de Courcy et al., 2008). These analyses showed on the other hand that in the monoligated complexes of $\mathrm{Zn}$ (II) with both imidazole and ethanol, $\mathrm{E}_{2}$ had at equilibrium distance a larger weight than $\mathrm{E}_{1}$. Within $\mathrm{E}_{2}, \mathrm{E}_{\text {pol }}$ was the dominant contribution. These findings could be directly linked to the fact that the cysteinates do not have polarized lone pairs pointing towards $\mathrm{Zn}(\mathrm{II})$ whereas imidazole and ethanol have respectively one and two lone pairs in direct interaction with $\mathrm{Zn}(\mathrm{II})$. Thus Table 1 shows that each cysteinate (basins 2 and 4) which in the complex is devoid of Zn-facing lone pairs, can serve as an attractor of 3.5 electrons from $\mathrm{Zn}(\mathrm{II})$. Imidazole (basin 3) having a single polarizing lone pair can serve as an attractor of $3.9 \mathrm{Zn}$ (II) electrons, while ethanol (basin 5) having two polarizing lone pairs can delocalize up to $6.2 \mathrm{Zn}(\mathrm{II})$ electrons. Since the distance between $\mathrm{Zn}(\mathrm{II})$ and the $\mathrm{S}^{-}$core is longer than those between $\mathrm{Zn}(\mathrm{II})$ and the other atom lone-pairs, and the $\mathrm{S}^{-}$ core electrons are poorly polarizable, the interaction is different in nature. The present study is limited to the Zn-coordinating residues. Only Phe93 from the 'outershell' is included, since it was previously assumed to be important for stabilization (de Courcy et al., 2008). Our present objective is to highlight using ELF the extent of electronic redistribution taking place on each individual $\mathrm{Zn}$-coordinating residue caused by $\mathrm{Zn}(\mathrm{II})$ and 
Table 2 Electronic distribution by constitutive fragment of the ADH binding site

\begin{tabular}{|c|c|c|c|c|c|c|}
\hline \multirow[t]{2}{*}{ Basins } & \multicolumn{3}{|c|}{ Uncomplexed fragments } & \multicolumn{3}{|c|}{ Complex } \\
\hline & & Volumes $\AA^{3}$ & Populations electron number & Volumes $\AA^{3}$ & Populations electron number & \\
\hline $\mathrm{V}(\mathrm{S})$ & Cysteinate & 175,70 & 2,30 & 125,78 & 2,58 & Cys46 \\
\hline $\mathrm{V}(\mathrm{S})$ & & 169,87 & 2,27 & 158,62 & 3,70 & \\
\hline $\mathrm{V}(\mathrm{S})$ & & 123,94 & 1,71 & & & \\
\hline Sum & & & 6,28 & & 6,28 & \\
\hline $\mathrm{V}(\mathrm{N} 1)$ & Imidazole & 116,22 & 2,90 & 61,69 & 2,90 & His67 \\
\hline $\mathrm{V}(\mathrm{S})$ & Cysteinate & 175,70 & 2,30 & 120,88 & 3,14 & Cys174 \\
\hline $\mathrm{V}(\mathrm{S})$ & & 169,87 & 2,27 & 155,35 & 3,14 & \\
\hline $\mathrm{V}(\mathrm{S})$ & & 123,94 & 1,71 & & & \\
\hline Sum & & & 6,28 & & 6,28 & \\
\hline $\mathrm{V}(\mathrm{O})$ & Ethanol & 55,73 & 2,36 & 39,22 & 2,47 & Ethanol \\
\hline $\mathrm{V}(\mathrm{O})$ & & 50,94 & 2,29 & 25,56 & 2,18 & \\
\hline Sum & & & 4,65 & & 4,65 & \\
\hline
\end{tabular}

the other $\mathrm{Zn}$-coordinating residues. It will be of interest for future studies to expand the site to other, outer-shell residues, on account of the results reviewed by Dudev and Lim (Dudev and Lim, 2003) showing that such residues could play an important role in charge redistribution. This is, however, outside of the scope of the present work.

\section{Conclusion}

We illustrate in this study the importance of electron density plasticity within the active site of the alcohol dehydrogenase Zn-metalloenzyme. Our results demonstrate that the number of lone pair ligands in direct interaction with $\mathrm{Zn}$ (II) can directly control the physical nature of the interaction namely mainly electrostatic or covalent/ionic. Indeed, such interactions appear to be increasingly dominated by polarization when the number of directly interacting ligands lone pairs increases. That way, responding to the ligands, the polarized metal cation is able to split its density outer shells and then to delocalize its electrons towards them. The amount of delocalized electrons (and corresponding volumes of the cation density subdomains) is clearly related to the ligand nature namely soft ligands such as the two cysteinates or harder ligands such as imidazole and ethanol. Moreover, we observe a peculiar behaviour of the $\mathrm{S}^{-}$cysteinate lone pairs which can redistribute between themselves and merge in order to reduce their number which helps to explain further its usually predicted soft character. These results confirm the remarkable plasticity of the electron density, which is at play in the active sites of metalloenzymes and which is linked to the softness/hardness concept. It also clearly indicates that the usual fixed VSEPR model used to build model force fields may not be always valid since the number of separated unbound electron pairs can vary upon electronic spatial relocation. However, it confirms the crucial importance of lone pairs (Piquemal et al., 2007; Piquemal and Pilmé, 2008) in the modelling of polarization phenomenon.

Acknowledgments The computations reported in this work were done in the computer centres of CRIHAN (Rouen, France), CINES (Montpellier, France) and CCRE (Paris, France). This work was supported in part by la Ligue Nationale contre le Cancer, Equipe Labellisée 2006 (U648).

\section{References}

[1] Bader, R.F.W. 1990. Atoms in Molecules-A Quantum Theory. Oxford University Press, Oxford.

[2] Becke, A.D. 1988. Correlation energy of an inhomogeneous electron gas: A coordinate-space model. J Chem Phys 88, 1053-1062.

[3] Becke, A.D., Edgecombe, K.E. 1990. A simple measure of electron localization in atomic and molecular systems. J Chem Phys 92, 5397-5403.

[4] Crow, K.E., Hardman, M.J. 1989. Regulation of rates of ethanol metabolism. In: Crow, K.E., Batt, R.D. (eds) Human Metabolism of Alcohol, Vol. 2. CRC Press, Boca Raton, 3-16.

[5] de Courcy, B., Piquemal, J.-P., Gresh, N. 2008. Energy analysis of $\mathrm{Zn}$ polycoordination in a metalloprotein environment and of the role of a neighboring aromatic residue. What is the impact of polarization? J Chem Theo Comput 4, 1659-1668.

[6] Dudev, T., Lim, C. 2003. Principles governing Mg, Ca, and $\mathrm{Zn}$ binding and selectivities in proteins. Chem Rev 103, 773-788.

[7] Frisch, M.J., Trucks, G.W., Schlegel, H.B., Scuseria, G.E., Robb, M.A., Cheeseman, J.R., Montgomery, J.A., Vreven, T., Kudin, K.N., Burant, J.C., Millam, J.M., Iyengar, S.S., Tomasi, J., Barone, V., Mennucci, B., Cossi, M., Scalmani, G., Rega, N., Petersson, G.A., Nakatsuji, H., Hada, M., Ehara, M., Toy- 
ota, K., Fukuda, R., Hasegawa, J., Ishida, M., Nakajima, T., Honda, Y., Kitao, O., Nakai, H., Klene, M., Li, X., Knox, J.E., Hratchian, H.P., Cross, J.B., Bakken, V., Adamo, C., Jaramillo, J., Gomperts, R., Stratmann, R.E., Yazyev, O., Austin, A.J., Cammi, R., Pomelli, C., Ochterski, J.W., Ayala, P.Y., Morokuma, K., Voth, G.A., Salvador, P., Dannenberg, J.J., Zakrzewski, V.G., Dapprich, S., Daniels, A.D., Strain, M.C., Farkas, O., Malick, D.K., Rabuck, A.D., Raghavachari, K., Foresman, J.B., Ortiz, J.V., Cui, Q., Baboul, A.G., Clifford, S., Cioslowski, J., Stefanov, B.B., Liu, G., Liashenko, A., Piskorz, P., Komaromi, I., Martin, R.L., Fox, D.J., Keith, T., Al-Laham, M.A., Peng, C.Y., Nanayakkara, A., Challacombe, M., Gill, P.M.W., Johnson, B., Chen, W., Wong, M.W., Gonzalez, C., Pople, J.A. 2007. Gaussian 03, Revision C.02. Gaussian Inc., Wallingford, CT.

[8] Garmer, D.R., Gresh, N. 1994. A comprehensive energy component analysis of the interaction of hard and soft dications with biological ligands. J Am Chem Soc 116, 3556-3567.

[9] Gillespie, R.J., Robinson, E.A. 2005. Models of molecular geometry. Chem Soc Rev 34, 396-407.

[10] Gourlaouen, C., Gérard, H., Piquemal J.-P., Parisel, O. 2008. Understanding lead chemistry from topological insights: the transition between holo- and hemidirected structures within the $[\mathrm{Pb}(\mathrm{CO}) \mathrm{n}]^{2+}$ model series. Chem Eur J 14, 2730-2743.

[11] Gresh, N, Stevens, W.J., Krauss, M. 1995. Mono- and polyligated complexes of $\mathrm{Zn}^{2+}$. An ab initio analysis of the metal-ligand interaction energy. J Comput Chem $16,843-855$.

[12] Gresh, N. 1995. Energetics of $\mathrm{Zn}^{2+}$ binding to a series of biologically-relevant ligands. A molecular mechanics investigation grounded on ab initio SCF supermolecular computations. J Comput Chem 16, 856-882.

[13] Gresh, N., Cisneros, Darden, T.A., Piquemal, J.P. 2007. Anisotropic, polarizable molecular mechanics studies of inter-, intra-molecular interactions, and ligand-macromolecule complexes. A bottom-up strategy. J Chem Theory Comput 3, 1960-1986.

[14] Krishnan, R., Binkley, J.S., Seeger, R., Pople, J.A. 1980. Self-consistent molecular orbital methods. XX. A basis set for correlated wave functions. J Chem Phys $72,650-654$.

[15] Lee, C., Yang, W., Parr, R.G. 1988. Development of the Colle-Salvetti correlation-energy formula into a functional of the electron density. Phys Rev B 37, 785789.

[16] Li, H., Hallows, W.H., Punzi, J.S., Pankiewicz, K.W., Watanabe, K.A., Goldstein, B.M. 1994. Crystallographic Studies of Isosteric NAD Analogues Bound to Alcohol Dehydrogenase: Specificity and Substrate Binding in Two Ternary Complexes. Biochemistry 33, 11734-11744.

[17] Maynard, A.T., Covell, D.G. 2001. Reactivity of Zinc Finger core: analysis of protein packing and electrostatic screening. J Am Chem Soc 123, 1047-1058.
[18] McLean, A.D., Chandler, G.S. 1980. Contracted Gaussian basis sets for molecular calculations. I. Second row atoms, Z=11-18. J Chem Phys 72, 5639-5648.

[19] Noury, S., Krokidis, X., Fuster, F., Silvi, B. 1999. Computational tools for the electron localization function topological analysis. Comput Chem 23, 597-604.

[20] Pilmé, J., Robinson E.A., Gillespie, R.J. 2006. Topological study of the geometry of $\mathrm{AF}_{6} \mathrm{E}$ molecules: Weak and inactive lone pairs. Inorg Chem 45, 6198 6204 .

[21] Pilmé, J., Piquemal, J.-P. 2008. Advancing beyond Charge Analysis using the Electronic Localization Function: Chemically Intuitive Distribution of Electrostatic Moments. J Comput Chem 29, 1440-1449.

[22] Piquemal, J.-P., Pilmé, J. 2006. Comments on the nature of the bonding in oxygenated dinuclear copper enzymes models. J Mol Struct: THEOCHEM 764, 7786.

[23] Piquemal, J.-P., Chelli, R., Procacci, P., Gresh, N. 2007. Key role of the polarization anisotropy of water in modeling classical polarizable force fields. J Phys Chem A 111, 8170-8176.

[24] Piquemal, J.-P., Pilmé, J., Parisel, O., Gérard, H, Fourré, I., Bergès, J., Gourlaouen, C., de la Lande, A., van Severen, M. C., Silvi, B. 2008. What can be learnt on biological or biomimetic systems with the topological analysis of the electron localization function? Int J Quant Chem 108, 1951-1969.

[25] Rassolov, V., Pople, J.A., Ratner, M., Windus, T.L. 1998. 6-31G* basis set for atoms $\mathrm{K}$ through Zn. J Chem Phys 109, 1223-1229.

[26] Schmidt, M.W., Baldridge, K.K., Boatz, J.A., Elbert, S.T., Gordon, M.S., Jensen, J.H., Koseki, S., Matsunaga, N., Nguyen, K.A., Su, S., Windus, T.L., Dupuis, M., Montgomery Jr, J.A. 1993. General atomic and molecular electronic structure system. J Comput Chem 14, 1347-1363.

[27] Silvi, B., Savin, A. 1994. Classification of chemical bonds based on topological analysis of electron localization functions. Nature 371, 683-686.

[28] Simonson, T., Claimet, N. 2002. CysxHisy-Zn ${ }^{2+}$ interactions: Thiol vs. thiolate coordination. Proteins: Structure, Function, and Genetics 49, 37-48.

[29] Stevens, W.J., Basch, H., Krauss, M. 1984. Compact effective potentials and efficient shared-exponent basis sets for the first- and second-row atoms. J Chem Phys 81, 6026-6033.

[30] Stevens, W.J., Fink, W.H. 1987. Frozen Fragment Reduced Variational Space Analysis of Hydrogen Bonding Interactions. Application to Water Dimer. Chem Phys Lett 139, 15-22.

[31] Zaric, S, Popovic, D.M., Knapp, E.W. 2000. Metal Ligand Aromatic Cation- $\pi$ Interactions in Metalloproteins: Ligands Coordinated to Metal Interact with Aromatic Residues. Chem Eur J 6, 3935-3942. 